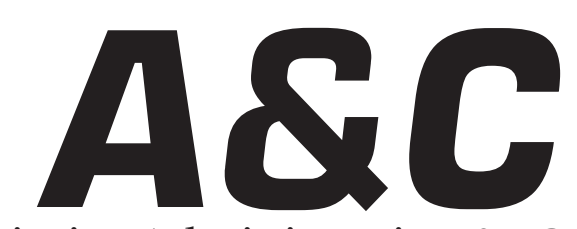

Revista de Direito Administrativo \& Constitucional

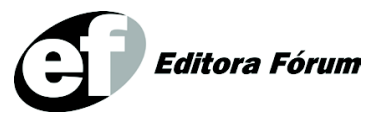

ISSN 1516-3210 


\section{A\&C REVISTA DE DIREITO ADMINISTRATIVO E CONSTITUCIONAL}

IPDA

Instituto Paranaense

de Direito Administrativo

Direção Geral

Romeu Felipe Bacellar Filho

Direção Editorial

Paulo Roberto Ferreira Motta

Direção Executiva

Emerson Gabardo

Conselho de Redação

Edgar Chiuratto Guimarães

Adriana da Costa Ricardo Schier

Célio Heitor Guimarães

\section{Conselho Editorial}

Adilson Abreu Dallari

Alice Gonzáles Borges

Carlos Ari Sundfeld

Carlos Ayres Britto

Carlos Delpiazzo

Cármen Lúcia Antunes Rocha

Celso Antônio Bandeira de Mello

Clèmerson Merlin Clève

Clóvis Beznos

Enrique Silva Cimma

Eros Roberto Grau

Fabrício Motta

Guilhermo Andrés Muñoz (in memoriam)

Jaime Rodríguez-Arana Muñoz

Jorge Luís Salomoni

José Carlos Abraão
José Eduardo Martins Cardoso
José Luís Said
José Mario Serrate Paz
Juan Pablo Cajarville Peruffo
Juarez Freitas
Julio Rodolfo Comadira
Luís Enrique Chase Plate
Lúcia Valle Figueiredo
Manoel de Oliveira Franco Sobrinho
(in memoriam)
Marçal Justen Filho
Marcelo Figueiredo
Márcio Cammarosano
Maria Cristina Cesar de Oliveira

Nelson Figueiredo

Odilon Borges Junior

Pascual Caiella

Paulo Eduardo Garrido Modesto

Paulo Henrique Blasi

Paulo Neves de Carvalho (in memoriam)

Paulo Ricardo Schier

Pedro Paulo de Almeida Dutra

Regina Maria Macedo Nery Ferrari

Rogério Gesta Leal

Rolando Pantoja Bauzá

Sérgio Ferraz

Valmir Pontes Filho

Yara Stropa

Weida Zancaner

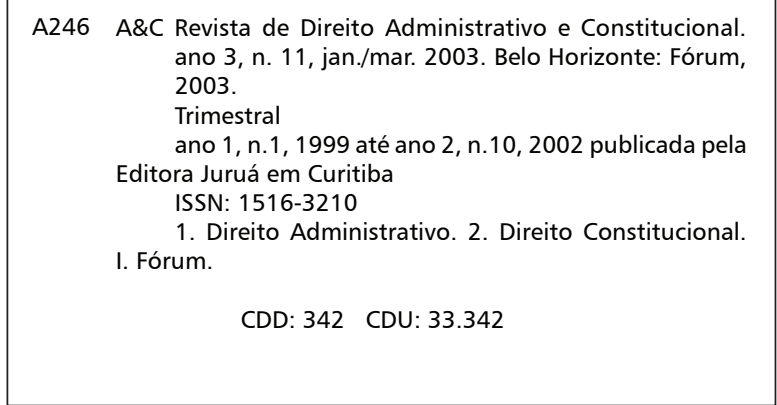

(c) Editora Fórum Ltda. 2006

Todos os direitos reservados. É proibida a reprodução total ou parcial, de qualquer forma ou por qualquer meio eletrônico ou mecânico, inclusive através de processos xerográficos, de fotocópias ou de gravação, sem permissão por escrito do possuidor dos direitos de cópias (Lei $n^{\circ}$ 9.610, de 19.02.1998).

Editora Fórum Ltda

Av. Afonso Pena, 2770 - 15\%16ª andar - Funcionários

CEP 30130-007 - Belo Horizonte/MG - Brasil

Tel.: 08007043737

Internet: www.editoraforum.com.br

e-mail: editoraforum@editoraforum.com.br
Editor responsável: Luís Cláudio Rodrigues Ferreira Projeto gráfico e diagramação: Luis Alberto Pimenta Revisora: Olga M. A. Sousa

Pesquisa jurídica: Fátima Ribeiro - OAB/MG 74868

Bibliotecária: Alessandra Rodrigues da Silva - CRB 2778/

MG 6a Região

Os conceitos e opiniões expressas nos trabalhos assinados são de responsabilidade exclusiva de seus autores.

Impressa no Brasil / Printed in Brazil

Distribuída em todo Território Nacional 


\title{
Dimensões normativas, temporais e político-sociais da revisão do ato administrativo no Brasil: possibilidades
}

Rogério Gesta Leal

Desembargador do Tribunal de Justiça do Estado do Rio Grande do Sul. Doutor em Direito. Professor Titular da Universidade de Santa Cruz do Sul. Professor Colaborador da Universidade Estácio de Sá. Professor Visitante da Università Túlio Ascarelli - Roma-Tre, Universidad de La Coruña - Espanha e Universidad de Buenos Aires

\begin{abstract}
Sumário: Notas introdutórias - 1 A revisão dos atos administrativos em face do decurso do tempo e dos direitos e garantias fundamentais - $2 \mathrm{O}$ direito adquirido como instituto densificador-material obstaculizante da revisão do ato administrativo - $3 \mathrm{O}$ problema da dimensão temporal à revisão do ato administrativo - Referências
\end{abstract}

Palavras-chave: Revisão do ato administrativo. Administração Pública. Poder Judiciário.

\section{Notas introdutórias}

Pretendo neste trabalho avaliar as condições e possibilidades da Administração Pública revisar os seus atos, bem como o Poder Judiciário, em face de alguns condicionantes normativos, temporais e atinentes à política jurídica, notadamente em face dos impactos sociais que isto pode acarretar.

Para tanto, vou enfrentar, num primeiro momento, a questão que envolve como se tem tratado do tema da revisão destes atos em nível doutrinário e jurisprudencial no país, destacando os elementos dogmáticos mais tradicionais na espécie, ao mesmo tempo em que estabelecendo uma crítica a eles a partir de referenciais mais reflexivos.

Num segundo momento, abordarei um dos centros neurais de aferição da possibilidade da revisão do ato administrativo que é o direito adquirido e seus consectários, também colacionando o que a casuística e a literatura dogmática no país tem elaborado quanto a isto.

Por fim, trago à colação a discussão sobre os limites temporais da revisão do ato administrativo, aspecto mais movediço e controverso de toda a celeuma, propondo uma alternativa à sua delimitação. 


\section{e dos direitos e garantias fundamentais}

Historicamente é possível se afirmar que a Administração Pública pode (e deve) anular seus próprios atos, quando eivados de ilegalidades, como preconiza a Súmula do STF (verbete 473). Contudo, essa regra comporta algum temperamento, especialmente quando a revisão se depara com o direito de servidor público afetado pelo ato revisor.

Sobre este tema, importa reconhecer que a hegemônica doutrina nacional e internacional tem se posicionado ao longo do tempo no sentido de entender que pode a Administração utilizar de seu poder de autotutela, possibilitando-lhe anular ou revogar seus próprios atos, quando eivados de nulidades, preservando-se, entretanto, a estabilidade das relações jurídicas firmadas, respeitando-se o direito adquirido e incorporado ao patrimônio material e moral do particular. ${ }^{1}$

Pontes de Miranda, já em seu Tratado de direito privado, asseverava que há determinados limites à revisão de atos, fatos e negócios jurídicos delimitados pelo próprio sistema jurídico, dentre outras formas, pela via da prescrição. Esta, serve à paz social e à segurança jurídica. Não destroem o direito, que é; não cancelam, não apagam as pretensões; apenas, encobrindo a eficácia da pretensão, atendem à conveniência de que não perdure por demasiado tempo a exigibilidade ou a acionalidade. ${ }^{2}$

O festejado autor não discrepa sobre a natureza do interesse quando o tema é prescrição, eis que para ele ela atinge todas as pretensões, quer se trate de direitos pessoais, quer de direitos reais, privados ou públicos. ${ }^{3}$

Tais ponderações vão na direção da necessidade que a própria lógica do sistema jurídico vigente impõe, ou seja, que se estabilizem as situações nas relações entre o Administrado e o Poder Público no tempo, isto porque, como quer Parejo Alfonso, a segurança jurídica opera como resultado de um conjunto de técnicas normativas dirigidas a garantir a própria densidade do sistema, que tem no fato consumado um centro neural. ${ }^{4}$

\footnotetext{
1 Neste sentido, ver os trabalhos, dentre outros, de: BONNARD. Précis de droit administratif; CARABBA. La valutazione e il controllo strategico. In: IL SISTEMA dei controlli interni nelle pubbliche amministrazioni; CRETELLA JR. Controle jurisdicional do ato administrativo; FERREIRA. A identidade da função de controle da Administração Pública. In: ROCHA, Cármen Lúcia Antunes (Coord.). Perspectivas do direito público: estudos em homenagem a Miguel Seabra Fagundes; FORSTHOFF. Tratado de derecho administrativo; FRAGOLA. Degli atti amministrativi; FROMONT. L'Etat moderne et I'administration; GIANINNI. Diritto amministrativo.

2 MIRANDA. Tratado de direito privado, v. 6, p. 137. Nas palavras do autor, a prescrição não atinge a ação, mas a pretensão, cobrindo a eficácia da pretensão e, pois, do direito, quer quanto à ação, quer quanto ao exercício do direito mediante cobrança direta, ou manifestação pretensional.

3 MIRANDA. Tratado de direito privado, v. 6, p. 163.
} 
E não se diga que os nominados atos nulos não podem ingressar no âmbito daquela lógica mencionada, porque em momento algum geram efeitos de qualquer natureza, pois, o direito positivo não diz absolutamente, nem no âmbito do privado, nem no público, que os atos nulos são imprescritíveis. Aliás, o direito positivo brasileiro nem ao menos descreve genericamente quais os atos administrativos nulos. Daí que não faz sentido sustentar a imprescritibilidade dos atos nulos no direito público, pois não há supedâneo algum para a tese. ${ }^{5}$

De outro lado, Reale insiste na tese de que, se a decretação de nulidade é feita muito tarde, e a inércia do Poder Público já oportunizou que se constituíssem situações de fato revestidas de forte aparência de legalidade, em nível de ensejar a convicção de sua legitimidade, afigurarse-ia irrazoável que se concedesse ao seu ius imperium um poder-dever eterno de revisão. ${ }^{6}$

O Superior Tribunal de Justiça, desde remoto acórdão de 1989, já teve oportunidade de ratificar a lógica que anima os argumentos realianos, mesmo que por reflexão envolvendo a preclusão e não a prescrição:

MANDADO DE SEGURANÇA. Ato Administrativo. Preclusão Administrativa. I - $\mathrm{O}$ ato administrativo conta com a retratabilidade que poderá ser exercida enquanto dito ato não gerar direitos a outrem; ocorrendo a existência de direitos, tais atos são atingidos pela preclusão administrativa, tornando-se irretratáveis por parte da própria Administração. II - É que, exercitando-se o poder da revisão de seus atos, a Administração tem que se ater aos limites assinalados na lei, sob pena de ferir o direito líquido e certo do particular, o que configura ilegalidade e ou abuso de poder. III - Segurança concedida. ${ }^{7}$

Outro elemento importante aqui é o que diz com a boa-fé daqueles que, confiando no Poder Público, podem, eventualmente, ser atingidos pela revisão de ato administrativo, notadamente quando não contribuíram em nada para ele. Esta boa-fé significa, nas palavras de Gonzalez Pérez, um verdadeiro valor ético atinente à confiança, representando uma das vias mais fecundas de afloramento do conteúdo ético e social no sistema jurídico; ela serve de leito à integração do ordenamento consoante algumas regras ético-materiais, como a idéia de fidelidade e crédito, de crença e confiança. ${ }^{8}$

Diogenes Gasparini, por sua vez, tem insistido no fato de que

\footnotetext{
4 PAREJO ALFONSO. Derecho administrativo, p. 119.

5 MELLO, C. Curso de direito administrativo, p. 286.

6 REALE. Revogação e anulamento do ato administrativo, p. 76.

BRASIL. Superior Tribunal de Justiça. MS 009-DF. Órgão julgador: 1a Sessão. Relator: Min. Pedro Accioli. Julgado em 31 out. 1989. Revista do Superior Tribunal de Justiça, Brasília, v. 17, p. 195, 1990.
} 
Nada justifica a possibilidade de um ato administrativo vir a ser declarado inválido depois de um longo tempo de sua edição. A entender-se isso factível, estar-se-ia pondo em risco a necessária estabilidade das relações jurídicas após certo tempo de vigência. Destarte, decorrido um determinado prazo, o ato, mesmo que inválido, firma-se, estabiliza-se, se não podendo mais ser invalidado pela Administração Pública ou anulado pelo Poder Judiciário. ${ }^{9}$

É o próprio Supremo Tribunal Federal que reconhece tal argumento, na medida em que já assentou considerar-se, hodiernamente, que o tema da proteção da confiança tem, entre nós, assento constitucional (princípio do Estado de Direito) e está disciplinado, parcialmente, no plano federal, na Lei no 9784, de 29 de janeiro de 1999, (v.g. art. $\left.2^{\circ}\right){ }^{10}$

Este posicionamento da Suprema Corte não é novo, eis que desde há muito vem se construindo uma percepção jurisdicional nesta direção, ex vi os seguintes extratos de acórdãos:

ATO ADMINISTRATIVO. Seu tardio desfazimento, já criada situação de fato e de direito, que o tempo consolidara. Circunstância excepcional a aconselhar a inalterabilidade da situação decorrente do deferimento da liminar, daí a participação no concurso público, com aprovação, posse exercício. Recurso Extraordinário não conhecido. ${ }^{11}$

A presunção de legitimidade dos atos administrativos milita não só em favor de pessoas jurídicas de direito público, como também do cidadão que se mostra, de alguma forma por eles alcançado. Logo o desfazimento, ainda que sob o ângulo da anulação, deveria ter ocorrido em cumprimento irrestrito ao que entende como devido processo legal (lato senso) e que o inciso LV, do art. $5^{\circ}$, objetiva preservar. ${ }^{12}$

Tais elementos considerados formariam, na dicção de Weida Zancaner, o que se denomina de barreiras ao dever de invalidar, as quais, em síntese, se resumem na assertiva de que

Os atos inválidos geram conseqüências jurídicas, pois se não gerassem não haveria qualquer razão para nos preocuparmos com eles. Com base em tais atos, certas situações terão sido instauradas e, na dinâmica da realidade, podem converter-se em situações merecedoras de proteção, seja porque encontrarão em seu apoio alguma regra específica, seja porque estarão abrigadas por algum princípio de direito. Estes fatos posteriores à constituição da relação inválida, aliados ao

\footnotetext{
8 GONZALEZ PEREZ. El princípio general de la buena fe em el derecho administrativo, p. 23. Na mesma direção o texto de GARCÍA DE ENTERRÍA. Reflexiones sobre la ley y los princípios generales del derecho, p. 39 et seq.

9 GASPARINI. Direito administrativo, p. 102

${ }^{10}$ BRASIL. Supremo Tribunal Federal. MS n 24.268/MG. Órgão julgador: Pleno. Relator: Acórdão Min. Gilmar Ferreira Mendes. Julgado em 05 fev. 2004. DJ, Brasília, 17 set. 2004.

${ }^{11}$ BRASIL. Supremo Tribunal Federal. RE $n^{\circ}$ 85179/RJ. Julgado pela $1^{\text {a }}$ Turma, tendo como Relator o Min. Bilac Pinto, julgado em 04 nov. 1977. DJ, 02 mar. 1978.

12 BRASIL. Supremo Tribunal Federal. RE no 158.543-9/RS. Oriundo da $2^{\text {a }}$ Turma, tendo como Relator o Min. Marco Aurélio, julgado em 30 ago. 1994. DJ, 10 out. 1994.
} 
tempo, podem transformar o contexto em que esta se originou, de modo que a que fique vedado à Administração Pública o exercício do dever de invalidar, pois fazê-lo causaria ainda maiores agravos ao Direito, por afrontar a segurança jurídica e a boa-fé. ${ }^{13}$

Como sopesar, pois, na espécie, o dever do Estado (Judiciário, Executivo ou Legislativo) em revisar atos praticados reputados como nulos, em face da constância de tais atos no tempo, notadamente quando implicam implementação e consolidação de direitos subjetivos em patrimônio e interesses alheios?

Veja-se que a situação induz ao reconhecimento do confronto entre os princípios da legalidade e o da segurança jurídica. Para equalizá-los em face do caso, mister é que façamos uma ponderação dos interesses envolvidos e protegidos pelo sistema normativo vigente, e isto a partir de uma hermenêutica constitucional de concordância prática, que, na dicção de Canotilho, impõe a coordenação e combinação dos bens jurídicos em conflito ou em concorrência de forma a evitar o sacrifício (total) de uns em relação aos outros. ${ }^{14}$

Neste sentido, com José Carlos Vieira de Andrade, tenho que o nível de restrição de cada bem jurídico será inversamente proporcional ao peso que se emprestar, no caso, ao princípio do qual ele se deduzir, e diretamente proporcional ao peso que se atribuir ao princípio protetor do bem jurídico concorrente. Assim, o grau de compressão a ser imposto a cada princípio envolvido na questão dependerá da intensidade com que o mesmo venha a ser afetado no caso concreto. ${ }^{15}$

Na espécie, quando a Administração Pública pretende revisar ato administrativo maculado por algum vício que o inquinou, implicando tal pretensão efeitos de caráter patrimonial ou extra-patrimonial violadores de direitos e garantias individuais ou coletivas protegidos, em tese, pelo próprio sistema jurídico que lhe autoriza agir, mister é que, primeiro, garanta o espaço de devido processo legal constitucional e processual, oportunizando o exercício de defesa ampla. Ao depois, mister é que seja avaliada ainda a possibilidade jurídica substancial dos bens jurídicos tutelados no particular, em face mesmo do direito material envolvido na

\footnotetext{
13 ZANCANER. Da convalidação e da invalidação dos atos administrativos, p. 65. Vai na mesma direção os trabalhos de FAGUNDES. Revogação e anulamentos do ato administrativo, p. 81.

${ }^{14}$ CANOTILHO. Direito constitucional, p. 234.

15 ANDRADE. Os direitos fundamentais na Constituição Portuguesa de 1976, p. 222. Ver também o trabalho de DELGADO. Direito adquirido nas relações de direito privado e nas relações de direito público. Jurisprudência Brasileira, cível e comércio, p. 14.
} 
espécie, pois, se de natureza indisponível (como os direitos humanos e fundamentais, ou atinentes às demais cláusulas pétreas da Constituição), ${ }^{16}$ incidirão no sopesamento deles toda a carga vinculativa dos vetores axiológico-normativos deste sistema a protegê-los (como os princípios constitucionais, os direitos e garantias fundamentais, etc.). ${ }^{17}$

$\mathrm{Na}$ diç̧ão de Larenz, isto ocorre porque aqueles vetores são verdadeiras pautas orientadoras da normatividade jurídica de todo o sistema, tendo a função de persuasão como de justificação de decisões administrativas ou jurídicas de toda e qualquer ordem. ${ }^{18}$

Numa direção mais pragmática, se pode dizer que, desde uma teoria axiológica dos direitos fundamentais (que parte, dentre outras, da teoria da integração de Rudolf Smend ${ }^{19}$ e chega até Robert Alexy ${ }^{20}$ ), aqueles princípios fixam valores fundamentais da comunidade, formando um sistema de bens jurídicos passíveis de tutela — singular ou coletiva; um sistema cultural, através do qual, os indivíduos alcançam um status material e substantivo.

Dentre aqueles vetores referidos, podemos destacar, por oportuno ao debate proposto, o do direito adquirido, instituto constitucional densificador material do que até agora ponderamos, o qual merece especial destaque.

\section{0 direito adquirido como instituto densificador-material obstaculizante da revisão do ato administrativo}

Desde Gabba, no mínimo, o direito adquirido advém: a) de um fato idôneo a produzi-lo, em virtude da lei do tempo em que esse fato foi realizado, embora a ocasião de o fazer valer não se tenha apresentado antes do surgimento de uma lei nova sobre o mesmo; b) dos termos da lei, sob o império da qual se deu o fato de que se originou, tenha entrado imediatamente para o patrimônio de quem o adquiriu. ${ }^{21}$

No âmbito da legislação ordinária brasileira, este instituto vem delimitado nos precisos termos do art. $6^{\circ}, \S 2^{\circ}$, da LICC, com a redação que lhe deu a Lei $n^{\circ} 3.238$, de 01.8.57, de acordo com a qual: Consideram-se adquiridos os direitos que o seu titular, ou alguém por ele, possa exercer, como aqueles

\footnotetext{
${ }^{16} \mathrm{E}$ em qualquer caso, haja vista que estamos destacando aqui o caso sob análise.

${ }^{17}$ Abordamos este tema nos textos: LEAL, Rogério Gesta. Perspectivas hermenêuticas dos direitos humanos

e fundamentais no Brasil. Porto Alegre: Livraria do Advogado, 2001; LEAL, Rogério Gesta. Estado, Administração Pública e Sociedade: novos paradigmas. Porto Alegre: Livraria do Advogado, 2006.

18 LARENZ. Metodologia da ciência do direito, p. 24 et seq.

${ }^{19}$ Como quer SMEND. Filosofia del derecho, p. 86 et seq.

${ }^{20}$ ALEXY. Teoria de los derechos fundamentales, 1997.
}

A \& C R. de Dir. Administrativo e Constitucional, Belo Horizonte, ano 6, n. 26, p. 141-159, out./dez. 2006 
cujo começo do exercício tenha termo prefixo, ou condição preestabelecida inalterável, a arbítrio de outrem.

Talvez um dos grandes debates fundamentais sobre esta matéria é o que diz respeito ao direito adquirido em face da Constituição. Em linhas gerais, tem-se dito que o direito adquirido diz com as leis ordinárias e não com a CF, que incide imediatamente por força de sua própria natureza e em vista da posição hierárquica que ocupa. A unidade de tratamento legal no que diz com as principais questões da nação exige a supremacia da ordem constitucional. ${ }^{22}$ De outro lado, não há direito adquirido para que seja aplicada uma lei considerada inconstitucional. E se a lei somente vem a ser tida como inconstitucional posteriormente? Mesmo assim, não se forma o direito adquirido. As situações criadas ou erigidas quando ainda valia a lei não ficam resguardadas contra a inconstitucionalidade. É que a declaração de inconstitucionalidade opera ex tunc com a nulidade de pleno direito de todos os atos praticados sob o manto do texto inconstitucional. ${ }^{23}$

Da mesma forma candente é a questão que relaciona o direito adquirido à expectativa de direito. Neste sentido, há uma divisão doutrinária e mesmo jurisprudencial no país tratando da matéria, uma delas, defendendo que, se a pessoa não começou a exercer o direito, não possui direito adquirido. Tem apenas uma faculdade, uma capacidade não exercida. Conseqüentemente, goza de direito adquirido quem iniciou o ato de onde ele promanou. ${ }^{24}$ Outros, defendem que a pessoa não perde o direito porque não o exerceu antes da revogação da lei que o concedia, ou antes do surgimento de lei nova dispondo uma situação bem diferente. ${ }^{25}$

Pontes de Miranda asseverava que não se pode dividir o domínio das leis segundo a sucessão dos fatos: fatos passados, regidos por leis anteriores; fatos presentes, pelas leis do presente; fatos futuros, pelas leis do futuro. O que se tem de dividir é o tempo: passado, regido pela lei do passado; presente, pela lei do presente; futuro, pela lei do futuro. Quando se fala em sobrevivência da lei antiga, em verdade se cai em grave engano; o que nos dá a ilusão da sobrevivência é o fato de confundirmos incidência e aplicação da lei; o que consideramos efeito de invasão da lei antiga no

\footnotetext{
${ }^{21}$ GABBA. Teoria della retroatività delle leggi, p. 82.

22 Nesta linha, se a validade dos concursos para o ingresso na função pública é de quatro anos, e a Constituição vem a reduzir o prazo para dois anos, eventual candidato aprovado e ainda não nomeado

direito algum terá para que prevaleça o prazo anteriormente previsto.

${ }^{23}$ Neste sentido, ver o texto de SILVA, J. Direito constitucional positivo, p. 85

${ }^{24}$ Conforme CAVALCANTI. Tratado de direito administrativo, p. 62.

${ }^{25}$ Assim MELLO, O. A teoria das Constituições rígidas.
} 
presente é derivado de pensarmos que a lei incide quando a aplicamos: a lei já incidiu; a aplicação é, apenas, o dizer-se que a lei já incidiu. ${ }^{26}$

Em síntese apertada, pode-se dizer com Serpa Lopes que são os seguintes elementos que compõem a estrutura geral do direito adquirido: o surgimento de um fato idôneo ou jurídico; a existência de uma lei que lhe dá a envergadura jurídica; a integração ao patrimônio material ou moral do sujeito; a prevalência ante o aparecimento de lei nova, dispondo diversamente sobre o mesmo assunto, ainda que não se fez valer quando do advento da lei nova. ${ }^{27}$

O fundamental, pois, é a proteção dos bens jurídicos envolvidos para a segurança das relações jurídicas. Note-se, todavia, que o respeito aos direitos adquiridos não veda a sua restrição, nem mesmo sua eliminação por lei posterior à sua aquisição. Apenas significa que essa restrição ou supressão só tem efeitos para o futuro. Do contrário, o legislador seria praticamente impotente, já que toda alteração de leis, ou edição de novas, atinge, do instante da publicação em diante, direitos adquiridos.

No campo da gestão endógena da Administração Pública, a jurisprudência e a doutrina têm pacificado o entendimento de que a mudança de orientação da Administração é válida, mas só se aplica ao futuro, não podendo alcançar situações pretéritas.

Também neste ponto o Supremo Tribunal Federal desde há muito vem reconhecendo que descabe a mudança de interpretação de atos normativos em prejuízo da parte, pois, decidida a questão, não poderia, a seu juízo, ser reaberta a interpretação. ${ }^{28}$

A matéria chegou a merecer Súmula do STF ( ${ }^{\circ} 473$ ), na qual foi salientado que: "a administração pode anular seus próprios atos quando eivado de vícios que os tornam ilegais”, mas só pode revogá-los desde que respeitados os direitos adquiridos.

No acórdão que ensejou a elaboração da Súmula referida, a corte, invocando a lição de Francisco Campos, entendeu ser inadmissível a modificação, por ato da Administração, de efeitos já produzidos por um ato administrativo anterior, concluindo que: "não se compreende que a Administração não se vincule por aquele ato da mesma maneira que o legislador é vinculado, ao editar a nova lei, pelos efeitos produzidos sob a vigência da lei anterior. Em outras palavras, a irretratabilidade

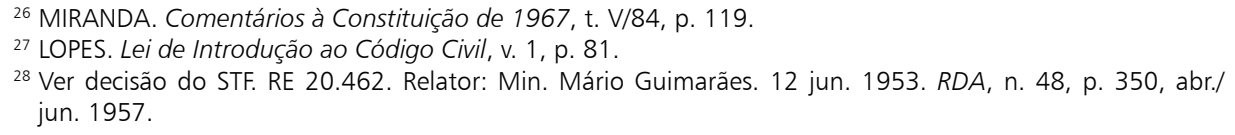

A \& C R. de Dir. Administrativo e Constitucional, Belo Horizonte, ano 6, n. 26, p. 141-159, out./dez. 2006 
dos atos administrativos, que produziram os seus efeitos, constitui um imperativo de segurança jurídica". ${ }^{29}$

Miguel Reale ${ }^{30}$ afirma que se a autoridade, no uso de seu poder discricionário, baixou ato legítimo e a sombra do mesmo se constituíram situações jurídicas, não pode a superveniente invocação do interesse público ter força para desfazer interesses legítimos aperfeiçoados.

Especificamente envolvendo o campo da Administração Pública, para Almiro do Couto e Silva, ${ }^{31}$ aos princípios da legalidade e da proteção da confiança ou da boa-fé dos administrados, ligam-se, respectivamente, a presunção ou aparência de legalidade que têm os atos administrativos e a necessidade de que sejam os particulares defendidos, em determinadas circunstâncias, contra fria e mecânica aplicação da lei, com o conseqüente anulamento de providências do Poder Público que geraram benefícios e vantagens, há muito incorporados ao patrimônio dos administrados.

Por tais razões, em nome do direito adquirido, da preservação da segurança e estabilidade das relações no mundo jurídico, há quem defenda desde há muito que, por vezes, o desfazimento de um ato administrativo pode causar mais caos na ordem jurídica do que sua simples mantença, ainda que seja o mesmo eivado de nulidade, ${ }^{32}$ o que sem sombra de dúvidas é de todo procedente.

De certa forma, o direito adquirido e um dos seus resultados mais diretos e importantes, a segurança jurídica, é pressuposto neural do Estado Democrático de Direito, eis que se afigura como indispensável para governantes e governados, pelas seguintes razões: (a) para os primeiros, a fim de que possam desempenhar plenamente suas atribuições, usando com o máximo de eficácia os instrumentos legais, tendo a certeza de que não irão sofrer, mais tarde, as conseqüências dos atos que tiveram prati-

\footnotetext{
${ }^{29}$ Ver decisão Ac. do MS 12.512. RF, n. 212, p. 89.

${ }^{30}$ REALE. Revogação e anulamento do ato administrativo, p. 39.

${ }^{31}$ SILVA, A. Prescrição qüinqüenária da pretensão anulatória da Administração Pública com relação a seus atos administrativos. Revista de Direito Administrativo, p. 46-63. Neste ponto, refere o autor que: $A$ Administração Pública brasileira, na quase generalidade dos casos, aplica o princípio da legalidade, esquecendo-se completamente do princípio da segurança jurídica. A doutrina e a jurisprudência nacionais, com as ressalvas apontadas, têm sido muito tímidas na afirmação do princípio da segurança jurídica.

${ }^{32}$ Assim o trabalho de ROCHA (Coord.). Perspectivas do direito público: estudos em homenagem a Miguel Seabra Fagundes. Há decisões jurisprudenciais nesta direção já na década de 1990: ENSINO SUPERIOR REGISTRO DE DIPLOMA - CURSO DE $2^{\circ}$ GRAU CONCLUÍDO - SITUAÇÃO FÁTICA CONSOLIDADA. CursO de $2^{\circ}$ grau concluído há mais de oito anos, cuja validade não foi contestada pela Faculdade Católica de Salvador, quando permitiu o ingresso do aluno e a sua permanência naquele estabelecimento de ensino até a conclusão de seu curso, não deve ser agora invalidado, pois há necessidade de se preservar uma situação que o tempo incumbiu de consolidar. Registro de diploma de nível superior que se defere
} 
cado como agentes do poder público; (b) para os segundos, afigura-se mais evidente ainda a necessidade de segurança jurídica, para que, sob pretexto de razão de Estado, não sofram o arbítrio e a violência, ficando à mercê de autoridades mal preparadas.

Se tivesse que densificar de maneira mais objetiva a forma com que a ordem constitucional delimita a importância do direito adquirido e da segurança jurídica no âmbito das relações intersubjetivas, poder-se-ia destacar: (1) a previsão normativa do devido processo legal, materializador da garantia de que ninguém será privado da liberdade ou de seus bens sem o devido processo legal (CF, art. $5^{\circ}$, LIV); (2) a garantia da inafastabilidade do controle jurisdicional, concretizador da garantia de que a lei não excluirá da apreciação do Poder Judiciário lesão ou ameaça a direito (CF, art. $5^{\circ}$, XXXV); (3) a submissão dos Poderes Públicos aos princípios da legalidade, impessoalidade, moralidade e publicidade, aos quais agregam-se, por decorrência implícita, os princípios da razoabilidade, proporcionalidade e motivação dos atos, todos assecuratórios de que em todos os níveis e setores da Administração Pública haverá a possibilidade de exercer um controle preventivo e curativo destes comportamentos, exigindo-se deles a efetiva transparência e adequação entre os meios e os fins (CF, art. 37).

Todos estes parâmetros constitucionais que estão a dar sentido ao direito adquirido e a salvaguardar a segurança jurídica das relações entre sujeitos de direito, em verdade, pretendem assegurar a eles não serem privados de seus bens e garantias sem o contraditório e a ampla defesa.

Em recente julgado, o Supremo Tribunal Federal, por seu pleno, por maioria, destacou que:

Mandado de Segurança. 2. Cancelamento de pensão especial pelo Tribunal de Contas da União. Ausência de comprovação da adoção por instrumento jurídico adequado. Pensão concedida há vinte anos. 3. Direito de defesa am-

Precedentes do ex-TFR e deste Tribunal. Apelo e remessa improvidos. Decisão mantida" (BRASIL. Tribunal Regional Federal (1. Região). Ac. unân. da $1^{\text {a }}$ T. Publicado em 22 abr. 1991. AMS 90.01.07444-8-BA Relator: Juiz Plauto Ribeiro) (Informativo Semanal - Adv/Coad 31/91 - p. 483).

ATO ADMINISTRATIVO - PRINCÍPIO DA LEGALIDADE - DESCONSTITUIÇÃO DESACONSELHÁVEL. O princípio da legalidade vincula o administrador não só à lei stricto sensu. Salvo raríssimas exceções, é imperioso, sob pena de nulidade, que o administrador dê as razões de fato e de direito determinantes do seu ato. Se a decisão judicial produz uma situação fática consolidada pelo decurso do tempo, sua desconstituição é desaconselhável, mormente quando não causa prejuízos a terceiros. Remessa oficial e recurso voluntário improvidos" (BRASIL. Tribunal Regional Federal (5. Região). Ac. unân. da $1^{\text {a }}$ T. Publicado em 19 abr. 1991. AMS 694-RN. Relator: Juiz Francisco Falcão) (Informativo Semanal - Adv/Coad 23/91 - p. 355). 
pliado com a Constituição de 1988. Âmbito de proteção que contempla todos os processos, judiciais ou administrativos, e não se resume a um simples direito de manifestação no processo. 4. Direito constitucional comparado. Pretensão à tutela jurídica que envolve não só o direito de manifestação e de informação, mas também o direito de ver seus argumentos contemplados pelo órgão julgador. 5. Os princípios do contraditório e da ampla defesa, assegurados pela Constituição, aplicam-se a todos os procedimentos administrativos. 6 . O exercício pleno do contraditório não se limita à garantia de alegação oportuna e eficaz a respeito de fatos, mas implica a possibilidade de ser ouvido também em matéria jurídica. 7. Aplicação do princípio da segurança jurídica, enquanto subprincípio do Estado de Direito. Possibilidade de revogação de atos administrativos que não se pode estender indefinidamente. Poder anulatório sujeito a prazo razoável. Necessidade de estabilidade das situações criadas administrativamente. 8. Distinção entre atuação administrativa que independe da audiência do interessado e decisão que, unilateralmente, cancela decisão anterior. Incidência da garantia do contraditório, da ampla defesa e do devido processo legal ao processo administrativo. 9. Princípio da confiança como elemento do princípio da segurança jurídica. Presença de um componente de ética jurídica. Aplicação nas relações jurídicas de direito público. 10. Mandado de Segurança deferido para determinar observância do princípio do contraditório e da ampla defesa $\left(\mathrm{CF}\right.$ art. $\left.5^{\circ} \mathrm{LV}\right) .^{33}$

Para Cínara Palhares, ${ }^{34}$ enfocando mais o tema da segurança jurídica, ela se revela como um verdadeiro princípio marcado pela característica da bidirecionalidade, isto é, vale tanto para as ações passadas quanto para as futuras. Com relação às ações passadas, esse princípio diz respeito à certeza do tratamento jurídico dado aos fatos já consumados, aos direitos adquiridos, a da força da coisa julgada (princípio da irretroatividade). Quanto ao futuro, a segurança jurídica diz com o sentimento de previsibilidade quanto aos efeitos jurídicos que advirão das condutas humanas, com a finalidade de permitir que os destinatários do direito organizem as suas ações na conformidade com o ordenamento jurídico.

Mesmo na dogmática jurídica há um consenso a este respeito, por exemplo, na dicção de Paulo de Barros Carvalho, ${ }^{35}$ ao sustentar que

O princípio da segurança jurídica é decorrência de fatores sistêmicos, dirigido à implantação de um valor específico, qual seja, o de coordenar o fluxo das inte-

\footnotetext{
${ }^{33}$ Autos MS 24268 / MG - MINAS GERAIS. MANDADO DE SEGURANÇA

Relatora: Min. Ellen Gracie. Relator p/ Acórdão: Min. Gilmar Mendes. Julgamento: 05 fev. 2004. Órgão Julgador: Tribunal Pleno. Publicação: DJ, p. 00053, 17 set. 2004; Ement., v. 02164-01, p. 00154; RDDP, n. 23, p. 133-151, 2005; RTJ, v. 00191-03, p. 00922. Na espécie, O Tribunal, por decisão majoritária, deferiu a segurança, nos termos do voto do Senhor Ministro Gilmar Mendes, vencidos a Senhora Ministra Ellen Gracie, Relatora, que a indeferia, e, na extensão da concessão, os Senhores Ministros Nelson Jobim, Carlos Velloso e Cezar Peluso. Votou o Presidente, Ministro Maurício Corrêa, redigindo o acórdão o Min. Gilmar Mendes.

34 PALHARES, Cínara. Princípios Constitucionais e consumeristas informadores do direito bancário. Revista Jurídica, p. 46.
} 
rações inter-humanas, no sentido de propagar no seio da comunidade social o sentimento de previsibilidade quanto aos efeitos jurídicos da relação da conduta. Tal sentimento tranqüiliza os cidadãos, abrindo espaço para o planejamento de ações futuras, cuja disciplina jurídica conhecem, confiantes que estão no modo pelo qual a aplicação das normas do direito se realiza.

Concordando com Celso Antônio Bandeira de Mello, se um dos interesses fundamentais do Direito é a estabilidade das relações constituídas, a pacificação dos vínculos estabelecidos, a fim de se preservar a ordem, no caso particular dos atos administrativos, tais características têm repercussão mais ampla, alcançando inúmeros sujeitos, uns direta e outros indiretamente, interferindo à ordem e estabilidade das relações sociais em escala muito maior. ${ }^{36}$

Assim é que não se pode confundir o poder que tem a Administração Pública, nos seus atos de gestão, observados os interesses indisponíveis a serem protegidos e efetivados, envolvendo a comunidade como um todo, com as conseqüências destes atos e os deveres decorrentes deles (tais como os ressarcitórios e indenizatórios, a título de exemplificação) ${ }^{37}$

De qualquer sorte, se é possível a revisão dos atos administrativos como a doutrina e a casuística tem acertadamente sustentado - , levando em conta, todavia, os limitadores acima referidos, uma questão que ainda atormenta de igual forma a experiência brasileira é a que diz com a dimensão temporal para esta revisão, o que passo a abordar.

\section{0 problema da dimensão temporal à revisão do ato administrativo}

Em termos de normativas regulatórias sobre até quando os atos administrativos podem ser revistos, à esfera federal, consoante o art. 54, parágrafo $1^{\circ}$, da Lei $n^{\circ} 9.784 / 99$, o prazo para anulação destes atos é de 05 (cinco) anos a partir de sua efetivação. ${ }^{38}$

Parte da jurisprudência nacional, todavia, entende que a Lei Federal $\mathrm{n}^{\circ}$ 9.784, de 29.01.1999, prevê tal possibilidade apenas no âmbito federal (artigos $1^{\circ}$ e 54), sendo inaplicável na seara municipal, pois, ao Município, e somente a ele, compete legislar sobre assuntos de interesse local, máxime em se tratando de servidores municipais (artigo 30, inciso I, da Constituição Federal).

\footnotetext{
${ }^{35}$ CARVALHO. Curso de direito tributário, p. 95.

${ }^{36}$ MELLO, C. Curso de direito administrativo, p. 416.

${ }_{37}$ De certa maneira esta questão tem a ver com a propulsão que se tem dado à necessidade do Estado Administrador ser eficiente sem, no entanto, demarcar conceitualmente de que eficiência está se falando. Neste sentido, recomento a leitura do texto de GABARDO. Eficiência e legitimidade do Estado.
} 
Nesse sentido a jurisprudência do Tribunal de Justiça do Estado do Rio Grande do Sul:

MANDADO DE SEGURANÇA - REVISÃO DE APOSENTADORIA POR NEGATIVA DE REGISTRO PELO TRIBUNAL DE CONTAS - O CONTRADITÓRIO E A AMPLA DEFESA SÃO DISPENSÁVEIS QUANDO A ADMINISTRAÇÃO APLICA A SÚMULA 473 DO STF SEM ATRIBUIR QUALQUER INFRAÇÃO AO SERVIDOR, CORRIGINDO MERA IRREGULARIDADE - NÃO SE APLICA A LEI FEDERAL No 9784/99 QUE ESTABELECE A PRESCRIÇÃO QÜINQÜENAL PARA A ADMINISTRAÇÂO REVER SEUS ATOS AOS PROCESSOS ENVOLVENDO SERVIDORES ESTADUAIS SENDO NECESSÁRIA LEI LOCAL DISPONDO A RESPEITO - LESÃO A DIREITO LÍQUIDO E CERTO QUE NÃO SE OSTENTA. Segurança denegada. (RIO GRANDE DO SUL. Tribunal de Justiça. Mandado de Segurança No 70014235378. Órgão julgador: Segundo Grupo de Câmaras Cíveis. Relator: João Carlos Branco Cardoso. Julgado em 11 abr. 2006).

AÇÃO RESCISÓRIA. ADMINISTRATIVO E PROCESSUAL CIVIL. EQUIPARAÇÃO SALARIAL. PROVENTOS DE APOSENTADORIA, REVISÃO. MUDANÇA DE REGIME. SERVIDORA CELETISTA, TRANSPOSTA PARA O REGIME ESTATUTÁRIO, COM BASE NA LEI COMPLEMENTAR N ${ }^{\circ}$ 10.098/94. EQUIPARAÇÃO ALCANÇADA SOB O VÍNCULO TRABALHISTA QUE NÃO SE TRANSPORTA, CESSANDO COM O INGRESSO NO REGIME ESTATUTÁRIO, UMA VEZ ROMPIDO O VÍNCULO CONTRATUAL EXISTENTE. APROVEITAMENTO DE DECISÃO FAVORÁVEL OBTIDA NA JUSTIÇA DO TRABALHO QUE NÃO ATINGE A NOVA SITUAÇÃO JURÍDICO-FUNCIONAL DA AUTORA. IMPOSSIBILIDADE JURÍDICA DE SE TRANSFERIR PARA O REGIME ESTATUTÁRIO, EM NOME DO APREGOADO PRINCÍPIO DA IRREDUTIBILIDADE DE VENCIMENTOS, DIREITO RECONHECIDO E DECORRENTE DO VÍNCULO EMPREGATÍCIO MANTIDO ANTERIORMENTE, SOB PENA DE SE CRIAR REGIME JURÍDICO HÍBRIDO. OBSERVÂNCIA DO PRINCÍPIO DA LEGALIDADE. OFENSA À COISA JULGADA E À DISPOSIÇÃO DE LEI EM SUA LITERALIDADE NÃO CONFIGURADA. PRESCRIÇÃA ADMINISTRATIVA INOCORRENTE. LEI No 9.784/99 (ART. 54) RESTRITA À ÓRBITA FEDERAL, NÃO SE APLICANDO NAS RELAÇÕES DOS SERVIDORES ESTADUAIS E MUNICIPAIS. ACCÃO RESCISÓRIA IMPROCEDENTE. (RIO GRANDE DO SUL. Tribunal de Justiça. Ação Rescisória $N^{o}$ 70011256377. Órgão julgador: Segundo Grupo de Câmaras Cíveis. Relator: Luiz Ari Azambuja Ramos. Julgado em 12 ago. 2005).

EMBARGOS INFRINGENTES. SERVIDORAS PÚBLICAS. MUNICÍPIO DE BENTO GONÇALVES. CONCURSO PÚBLICO NULO. POSSIBILIDADE DE DESCONSTITUIÇÃO DAS NOMEAÇÕES. DECADÊNCIA ADMINISTRATIVA. Preliminar. Inaplicabilidade da Súmula 293 do STF, pois a decisão

\footnotetext{
${ }^{38}$ Neste sentido, ver o MS n 6.566/DF. Relator p/acórdão: Ministro Peçanha Martins. DJU, 15 maio 2000, do STJ. Também do STJ o MS 7090 - Proc. 2000.00.68744-8 - DF. Órgão julgador: Terceira Seção. Relator: Jorge Scartezzini. DJ, p. 47, 13 ago. 2001.
}

A \& C R. de Dir. Administrativo e Constitucional, Belo Horizonte, ano 6, n. 26, p. 141-159, out./dez. 2006 
recorrida não foi submetida ao Plenário deste Tribunal. Mérito. Decadência do Poder Público para invalidar atos nulos. Inaplicabilidade da Lei Federal n. 9.784/99, pois restrita ao âmbito federal. Inaplicabilidade da Lei Municipal n. 3.474/04, pois posterior aos atos impugnados e com eficácia suspensa liminarmente em Ação Direta de Inconstitucionalidade perante esta Corte. Ausência, portanto, de legislação estabelecendo prazo para a Administração Pública invalidar atos nulos. Princípios da boa-fé e da segurança jurídica que não se sobrepõem, no caso concreto, ao princípio da legalidade. Possibilidade de o Poder Público desconstituir atos de nomeação e aposentação de servidores públicos que ingressaram no cargo por meio de concurso público nulo. Princípio da legalidade. Prevalência da disposição constitucional (artigo 37, inciso II). EMBARGOS INFRINGENTES DESACOLHIDOS. (RIO GRANDE DO SUL. Tribunal de Justiça. Embargos Infringentes no 70010318798 . Órgão julgador: Segundo Grupo de Câmaras Cíveis. Relator: Matilde Chabar Maia. Julgado em 11 fev. 2005).

Por este prima, portanto, os atos administrativos viciados podem ser revistos a qualquer tempo.

Não concordo com esta abordagem, tanto pelas razões acima deduzidas, como pelo fato de que, nas palavras de Lúcia Valle Figueiredo, o direito repele situações instáveis no tempo e expostas às intempéries de ordem técnico-burocrática e, ou, política, pelo simples fato de que situações jurídicas jamais são de mão única. ${ }^{39}$

Na esteira do tratamento normativo majoritário que o país tem dado à variação de tempo em que se poderiam revisar os atos administrativos, afigura-se hegemônico o prazo de cinco anos como regra geral, a iniciar pelo revisado art. 178, §10, VI, do antigo Código Civil Brasileiro; o Decreto Federal no 20.910/32; o Decreto Federal no 4.597/42; a Lei Federal $\mathrm{n}^{\mathrm{o}}$ 5.761/30; a Lei Federal $\mathrm{n}^{\circ}$ 2.221/54; a Lei Federal $\mathrm{n}^{\circ}$ 5.172/66.

A razão para tal, é a que defende Almiro do Couto e Silva, ao sustentar que a pretensão à invalidação dos atos administrativos, de que o povo, por seus cidadãos está investido, não é, e nem pode ser diferente da pretensão que tem o Poder Público de invalidar aqueles mesmos atos jurídicos. ${ }^{40} \mathrm{O}$ autor chega a referir que o prazo de cinco anos é o mais adequado, pois a própria Ação Popular (Lei Federal $n^{\circ} 4.717 / 65$ ), que cuida da proteção de interesses de ordem pública indisponíveis, em seu art. 21, prevê o prazo de cinco anos à sanação da invalidade.

A Medida Provisória n ${ }^{\circ}$ 1.708, de 30.6.1998, igualmente delimitou em cinco anos o prazo prescricional de ação punitiva da Administração Pública Federal, em face do exercício do seu poder de polícia, objetivando

${ }^{39}$ FIGUEIREDO. Curso de direito administrativo, p. 154.

A \& C R. de Dir. Administrativo e Constitucional, Belo Horizonte, ano 6, n. 26, p. 141-159, out./dez. 2006 
apurar violação à legislação em vigor. Da mesma forma, as Disposições Transitórias da Constituição vigente, em seu art. 19, assegurou estabilidade a servidores admitidos no serviço público sem concurso desde que estivessem em exercício, na data da promulgação da Carta Política, há pelo menos cinco anos.

Como adverte Clarissa Silva, no âmbito do Direito Administrativo mais se destaca ainda a necessidade de proteção e respeito à boa-fé dos administrados, em função das inúmeras prerrogativas que a Administração possui em face da posição destacada que ocupa no sistema jurídico, tendo seus atos a favor de si a presunção de legitimidade e autoexecutoriedade, possibilidade de invalidação e revogação, contratação com cláusulas exorbitantes, etc.. Por tais razões é que se revela ainda mais importante o respeito a estes postulados, sob pena do cidadão comum — dentre eles os servidores públicos — restarem em posição de absoluta submissão à força cogente do Poder Estatal. ${ }^{41}$

Por estes fundamentos é que parte da jurisprudência pátria contemporânea, a qual me filio, tem se posicionado para não permitir que a Administração Pública reveja a qualquer tempo os atos consolidadores de direitos subjetivos que se incorporaram ao patrimônio de servidor.

Em princípio, o que dificulta o firmar posicionamento a respeito do tema é a ausência de diploma legal por parte do Estado do Rio Grande do Sul, como já o fizeram vários Estados e a própria União, cuja disciplina adveio através da Lei no 9.784/99, estabelecendo limites para a aplicação da súmula 473 do Supremo Tribunal Federal, coibindo a anulação de todo e qualquer ato administrativo nulo ao bel prazer da Administração, impondo, para tanto, limite de tempo e ausência de boa-fé objetiva por parte do administrado beneficiário do ato considerado nulo. É de ser considerado equivocado o status de princípio quase absoluto, que este Órgão Colegiado, vem conferindo ao da legalidade no âmbito do Direito Administrativo. 3. E assim, na medida em que, na seara do moderno Direito da Administração Pública, quando em conflito com os demais princípios constitucionais e constitucionais administrativos e, principalmente, o princípio da boa-fé objetiva e o primado da segurança jurídica, tendo em consideração as circunstâncias do caso concreto, é de ser entendido deva ser ele flexibilizado, como único meio de se atingir a efetiva realização da Justiça. E, para a aferição do princípio preponderante em cada situação apresentada em juízo, nos casos em que exsurge o conflito entre princípios, o melhor critério a ser utilizado é o da análise da proporcionalidade e da razoabilidade.... Dessa feita, na hipótese sub judice, a Justiça do caso concreto só será

\footnotetext{
${ }^{40}$ SILVA, A. Prescrição qüinqüenária da pretensão anulatória da Administração Pública com relação a seus atos administrativos. Revista de Direito Administrativo, p. 30

${ }^{41}$ SILVA, C. Limites à invalidação dos atos administrativos, p. 117
}

A \& C R. de Dir. Administrativo e Constitucional, Belo Horizonte, ano 6, n. 26, p. 141-159, out./dez. 2006 
alcançada se aplicado o princípio da boa-fé objetiva, presente na espécie, e do primado da segurança jurídica, pois não há admitir-se, que após passados todos esses anos o status quo da autora sofra modificação. ${ }^{42}$

CONSTITUCIONAL. ADMINISTRATIVO. SERVIDOR PÚBLICO. REMUNERAÇÃO: GRATIFICAÇÃO CONCEDIDA COM BASE NA LEI 1.762/86, ART. 139, II, DO ESTADO DO AMAZONAS. INCONSTITUCIONALIDADE FRENTE À CF/1967, ART. 102, §2. EFEITOS DO ATO: SUA MANUTENÇÃO. Ponho-me de acordo com a conclusão do parecer. É que não perfilho a tese da constitucionalidade superveniente. A lei inconstitucional nasce morta. Todavia, os efeitos porventura produzidos podem se incorporar ao patrimônio dos administrados, tendo em vista, sobretudo, o princípio da boa-fé. No caso, ao recorrido foi concedida a gratificação quando de sua aposentadoria. Vinha ele percebendo essa gratificação, quando sobreveio a Constituição de 1988, que não contém a proibição que se inscrevia na $\mathrm{CF} / 1967$, art. 102, §2. Parece evidente que a concessão da gratificação, com a aposentadoria, deu-se com observância do princípio da boa-fé. Ela tem, por outro lado, caráter alimentar. Ora, retirá-la, a esta altura, quando ela, efeito da lei estadual, está placitada pela ordem jurídico-constitucional vigente, não teria sentido. Retirá-la, quando a sua concessão viu-se coberta pelo princípio da boa-fé, representaria ofensa a esse princípio, certo, convém registrar, que uma das razões mais relevantes para a existência do direito está na realização do que foi acentuado na Declaração da Independência dos Estados Unidos da América, de 1776, o direito do homem de buscar a felicidade. Noutras palavras, o direito não existe como forma de tornar amarga a vida dos seus destinatários, senão de fazê-la feliz. ${ }^{43}$

Cumpre referir que já tive oportunidade de me manifestar jurisdicionalmente em situação semelhante quando integrava a Primeira Câmara Especial Cível desta Corte, em decisão assim ementada:

REEXAME NECESSÁRIO. DIREITO ADMINISTRATIVO. SERVIDORA PÚBLICA. A CONDIÇÃO DE APOSENTADA DA SERVIDORA MUNICIPAL DESDE O ANO DE 1990 LHE GARANTE O RECONHECIMENTO DA INCORPORAÇÃO AO SEU PATRIMÔNIO JURÍDICO DOS BENEFÍCIOS DA INATIVIDADE, NÃO PODENDO A MUNICIPALIDADE, OITO ANOS APÓS, PRETENDER DESCONSTITUIR O ATO ADMINISTRATIVO QUE DEU CAUSA A ESTA SITUAÇÃO. CONFIRMADA A SENTENÇA DE PRI-

\footnotetext{
${ }^{42}$ RIO GRANDE DO SUL. Tribunal de Justiça. Apelação e Reexame Necessário No 70011850666 . Órgão julgador: Quarta Câmara Cível. Relator: Wellington Pacheco Barros. Julgado em 28 set. 2005.

${ }^{43} \mathrm{Ag}$. Reg. no Recurso Extraordinário 434.222-7-Amazonas. Órgão julgador: 2a Turma. Relator: Min. Carlos Velloso. Julgado em 14 jun. 2005. Da mesma forma o Superior Tribunal de Justiça, nos autos do no REsp 625511 / RS, Agravo Regimental no Recurso Especial nº 2004/0006800-6, julgado em 23.6.2004, pela $5^{a}$ Turma, da lavra do Eminente Ministro Gilson Dipp, asseverou que ADMINISTRATIVO E PROCESSUAL CIVIL. PRESCRIÇÃO ADMINISTRATIVA. ART. 54 DA LEI No 9784/99. PRECEDENTES. IPERGS. PENSÃO. FILHA SOLTEIRA. LEI ESTADUAL N. ${ }^{\circ}$ 7.672/82. APLICAÇÃO DA SÚMULA 182/STJ. RECURSO DESPROVIDO.I - Nos termos do art. 54 da Lei no 9784/99, o direito da Administração de anular os atos administrativos de que decorram efeitos favoráveis para os destinatários decai em cinco anos, contados da data em que foram praticados, salvo comprovada má-fé.Precedentes. II - As razões insertas na fundamentação do agravo regimental deve limitar-se a atacar o conteúdo decisório da decisão hostilizada. No presente caso, tal hipótese não ocorreu. Aplicável, à espécie, a Súmula no 182/STJ.III - Agravo interno desprovido. Publicado no DJ, p. 559, 02 ago 2004.
} 
MEIRO GRAU. (RIO GRANDE DO SUL. Tribunal de Justiça. Reexame Necessário No 70004686309. Órgão julgador. Relator: Rogério Gesta Leal. Julgado em 27 fev. 2003).

O que se está revelando, em verdade, com tais abordagens e perspectivas é que o agir administrativo tem de ser absolutamente constitucional, antes de qualquer coisa, ou seja, ele deve estar conformado à ordem constitucional e precipuamente obrigado à sua efetividade, sob pena de dar maior inadequado relevo ao plano da infraconstitucionalidade que marca o seu cotidiano operativo. Esta constitucionalização da Administração Pública, pois, amplia o leque de possibilidades interpretativas — sempre conformadas pela e para a Constituição — do Poder Público. ${ }^{44}$

\section{Referências}

ALEXY, Robert. Teoria de los derechos fundamentales. Madrid: Centro de Estúdios Constitucionales, 1997.

ANDRADE, José Carlos Vieira de. Os direitos fundamentais na Constituição Portuguesa de 1976. Coimbra: Almedina, 2002.

BINENBOJM, Gustavo. Uma teoria do direito administrativo. Rio de Janeiro: Renovar, 2006.

BONNARD, Roger. Précis de droit administratif. Paris: LGDJ, 2001.

CANOTILHO, José J. Gomes. Direito constitucional. Coimbra: Almedina, 2004.

CARABBA, Manin. La valutazione e il controllo strategico. In: IL SISTEMA dei controlli interni nelle pubbliche amministrazioni. Milano: Giuffrè, 2004.

CARVALHO, Paulo de Barros. Curso de direito tributário. São Paulo: Saraiva, 2002.

CAVALCANTI, Themístocles Brandão. Tratado de direito administrativo. São Paulo: Freitas Bastos, 1986.

CLÈVE, Clèmerson Merlin. O controle de constitucionalidade e a efetividade dos direitos fundamentais. In: SAMPAIO, José Adércio Leite (Org.). Jurisdição constitucional e direitos fundamentais. Belo Horizonte: Del Rey, 2003.

CRETELLA JR., José. Controle jurisdicional do ato administrativo. Rio de Janeiro: Forense, 1992.

DELGADO, José Augusto. Direito adquirido nas relações de direito privado e nas

\footnotetext{
${ }^{44}$ Ver neste sentido o trabalho de BINENBOJM. Uma teoria do direito administrativo. Na mesma direção, o texto de CLÈVE. O controle de constitucionalidade e a efetividade dos direitos fundamentais. In: SAMPAIO, José Adércio Leite (Org.). Jurisdição constitucional e direitos fundamentais, p. 388 et seq.
}

A \& C R. de Dir. Administrativo e Constitucional, Belo Horizonte, ano 6, n. 26, p. 141-159, out./dez. 2006 
relações de direito público. Jurisprudência Brasileira, cível e comércio, Curitiba, n. 101, p. 13-270, 1985.

FAGUNDES, Miguel Seabra. Revogação e anulamento do ato administrativo. Rio de Janeiro: Forense, 1968.

FERREIRA, Sérgio D'Andrea. A identidade da função de controle da Administração Pública. In: ROCHA, Cármen Lúcia Antunes (Coord.). Perspectivas do direito público: estudos em homenagem a Miguel Seabra Fagundes. Belo Horizonte: Del Rey, 2000.

FIGUEIREDO, Lúcia Valle. Curso de direito administrativo. São Paulo: Malheiros, 2001.

FORSTHOFF, Ernst. Tratado de derecho administrativo. Madrid: Druma, 1994.

FRAGOLA, Umberto. Degli atti amministrativi. Milano: Giuffrè, 1992.

FROMONT, Michel. L'Etat moderne et l'administration. Paris: LGDJ, 1997.

GABARDO, Emerson. Eficiência e legitimidade do Estado. São Paulo: Manole, 2003.

GABBA, C.F. Teoria della retroatività delle leggi. Milano: Utet, 1991.

GARCÍA DE ENTERRÍA, Eduardo. Reflexiones sobre la ley y los princípios generales del derecho. Madrid: Cuadernos Civitas, 2000.

GASPARINI, Diogenes. Direito administrativo. São Paulo: Saraiva, 2001.

GIANINNI, Massimo Severo. Diritto amministrativo. 3ª ed. Milano: Giuffré, 1988.

GONZALEZ PEREZ, Jesús . El princípio general de la buena fe em el derecho administrativo. Madrid: Civitas, 1997.

LARENZ, Karl. Metodologia da ciência do direito. Lisboa: Fundação Calouste Gulbenkian, 2000.

LEAL, Rogério Gesta. Estado, Administração Pública e Sociedade: novos paradigmas. Porto Alegre: Livraria do Advogado, 2006.

LEAL, Rogério Gesta. Perspectivas hermenêuticas dos direitos humanos e fundamentais no Brasil. Porto Alegre: Livraria do Advogado, 2001.

LOPES, Miguel Maria de Serpa. Lei de introdução ao Código Civil. Rio de Janeiro: Freitas Bastos, 1997. v. 1.

MELLO, Celso Antônio Bandeira de. Curso de direito administrativo. São Paulo: Malheiros, 2005.

MELLO, Oswaldo Aranha Bandeira de. A teoria das Constituições rígidas. São Paulo: José Bushatsky Ed., 1980.

MIRANDA, Pontes de. Comentários à Constituição de 1967. Forense: Rio de Janeiro, 1975. t. V/84.

A \& C R. de Dir. Administrativo e Constitucional, Belo Horizonte, ano 6, n. 26, p. 141-159, out./dez. 2006 
MIRANDA, Pontes de. Tratado de direito privado. São Paulo: Bookseller, 2000. v. 6.

PALHARES, Cínara. Princípios Constitucionais e consumeristas informadores do direito bancário. Revista Jurídica, Porto Alegre, n. 267, 2003.

PAREJO ALFONSO, Luciano. Derecho administrativo. Madrid: Arial, 2003.

REALE, Miguel. Revogação e anulamento do ato administrativo. Rio de Janeiro: Forense, 1990 .

ROCHA, Cármen Lúcia Antunes (Coord.). Perspectivas do direito público: estudos em homenagem a Miguel Seabra Fagundes. Belo Horizonte: Del Rey, 1995.

SILVA, Almiro do Couto e. Prescrição qüinqüenária da pretensão anulatória da Administração Pública com relação a seus atos administrativos. Revista de Direito Administrativo, Rio de Janeiro, v. 204, 1996.

SILVA, Almiro do Couto e. Princípios da legalidade da Administração Pública e da segurança jurídica no Estado de direito contemporâneo. Revista de Direito Público, São Paulo, n. 84, p. 46-63, 2001.

SILVA, Clarissa Sampaio. Limites à invalidação dos atos administrativos. São Paulo: Max Limonad, 2002.

SILVA, José Afonso da. Direito constitucional positivo. São Paulo: Malheiros, 2002.

SMEND, Rudolf. Filosofia del derecho. Madrid: Civitas, 1990.

ZANCANER, Weida. Da convalidação e da invalidação dos atos administrativos. São Paulo: Malheiros, 1996.

Informação bibliográfica deste texto, conforme a NBR 6023:2002 da Associação Brasileira de Normas Técnicas (ABNT):

LEAL, Rogério Gesta. Dimensões normativas, temporais e político-sociais da revisão do ato administrativo no Brasil: possibilidades. A\&C Revista de Direito Administrativo e Constitucional, Belo Horizonte, ano 6, n. 26, p. 141-159, out./dez. 2006. 